\title{
Competência em interpretação - um breve estudo da interpretação em língua B
}

\section{Competence in interpreting: a brief study into a B language interpreting}

Patrícia Gimenez Camargo*

Resumo: O presente artigo analisa a interpretação em língua B a partir do estudo do modelo de competência tradutória do PACTE (2003) e do Modelo dos Esforços de Gile (1995), para responder à indagação: as competências empregadas na tradução e na interpretação são da mesma natureza? O objetivo principal é verificar se a tradução e a interpretação utilizam as mesmas subcompetências e, além disso, se essas subcompetências atuam de mesma forma em ambos os processos.

Palavras-chave: Interpretação; Modelo de competência; Modelo dos Esforços; Subcompetências; Tradução e Interpretação.

Abstract: This paper analyses the interpretation into a $B$ language using the study of PACTE's translation competence model (2003) and Gile's Effort Model (1995), in order to answer the question: are competences in translation and in interpreting from the same nature? The main objective here is to verify if translation and interpreting use the same sub-competences and, additionally, if these sub-competences act in the same way in both processes.

Keywords: Interpreting; Competence model; Effort Model; Sub-competences; Translation and Interpreting.

\footnotetext{
* Mestre em Linguística pela Universidade Cruzeiro do Sul e professora de interpretação na Universidade Nove de Julho. E-mail: patriciatradinterprete@gmail.com
} 


\section{Ensino de tradução e estudos empírico- experimentais}

Atualmente, há uma busca para verificar como os tradutores traduzem através de estudos empírico-experimentais. Algumas perguntas direcionam essas pesquisas, entre elas, como se traduz e como se aprende a traduzir? Para refletir sobre essas e tantas outras perguntas, fez-se necessário desenvolver modelos de competência tradutória que abarcassem as subcompetências necessárias ao processo de tradução e que, com certeza, refletiriam em seu produto. Um dos modelos mais bem desenvolvidos é 0 modelo do grupo PACTE (1998, 2003), o qual contempla várias subcompetências que agem de forma integrada. Por outro lado, há uma preocupação em se estudar a interpretação e a atuação dos intérpretes de forma menos anedótica, uma vez que há diversos trabalhos que relatam casos sem o objetivo de discutir a interpretação com rigor. Na literatura em interpretação, destaca-se o Modelo dos Esforços proposto por GILE (1995), que busca estudar não somente o processo e o produto da interpretação, mas também discute as omissões, as adições e as perdas relacionadas ao processo de interpretação.

0 presente artigo abordará o modelo de competência tradutória do PACTE (2003) e o Modelo dos Esforços de GILE (1995), bem como apresentará a temática da interpretação para a língua estrangeira, denominada língua B. 0 objetivo principal é analisar se a tradução e a interpretação utilizam as mesmas subcompetências, e, além disso, se essas subcompetências atuam de forma análoga em ambos os processos. 


\section{1 Sobre competências}

A competência tradutória ou CT é, conforme nos ensina CINTRÃO (2006), um construto dos Estudos Tradutológicos. Em relação à definição de CT, podemos afirmar sua diversidade, uma vez que diferentes modelos foram propostos por vários autores, entre os quais WILLS, TouRY e KRINGS. No entanto, no escopo deste trabalho, apropriar-nos-emos do modelo de competência tradutória proposto pelo grupo PACTE (2003) a fim de fundamentar nossa discussão.

O grupo PACTE é constituído por professores de tradução que também são tradutores e que têm por preocupação o estudo do processo de aquisição de competência tradutória. O PACTE conduziu estudos para definir a CT e como desenvolvê-la. Vale ressaltar que o grupo se dedica ao estudo empíricoexperimental de CT. O primeiro modelo foi apresentado em 1998 e, após estudos, reformulado em 2003. Por limitação de espaço, apresentaremos somente o modelo de 2003 que consta de cinco subcompetências: a bilíngue, a instrumental, os conhecimentos sobre tradução, a extralinguística, e a competência estratégica como central. Além das subcompetências, temos como parte do modelo os conhecimentos psicofisiológicos. A CT é um conhecimento especializado que, ao ser adquirido, funciona no tradutor como um sistema subjacente de conhecimentos e habilidades que Ihe permitirão traduzir com competência. O grupo define a CT como "o sistema subjacente de conhecimentos necessários para se traduzir". (PACTE 2011: 31). As subcompetências são assim delineadas pelo grupo:

A subcompetência bilíngue inclui o conhecimento das línguas de trabalho e a capacidade de se evitar a transferência, ou seja, de uma língua influenciar na outra durante a tradução, pois ambas as línguas estarão em contato durante o processo. 
Por sua vez, a subcompetência instrumental visa abarcar os meios necessários para a produção da tradução. Estão incluídos os dicionários, as enciclopédias e os buscadores eletrônicos que auxiliarão o tradutor durante 0 processo de tradução.

Os conhecimentos sobre tradução envolvem o funcionamento da tradução, dos processos e métodos tradutórios, além de conhecimentos sobre o mercado de trabalho e sobre seu funcionamento.

A extralinguística refere-se aos conhecimentos que o tradutor detém: tais conhecimentos extrapolam o sistema da língua em si, como, por exemplo, o conhecimento geral de mundo, de diferentes culturas e da interação entre elas.

A competência estratégica é vista como central pelo grupo, uma vez que regula 0 processo de tradução em relação às escolhas do tradutor, ao planejamento da tradução e à decisão da apresentação do produto final. Ela é importante por integrar todas as outras e fazê-las funcionar de forma adequada.

Apesar de os componentes psicofisiológicos não serem definidos como uma subcompetência, eles integram o modelo porque regulam a memória, a atenção, a cognição, além dos aspectos atitudinais de tomada de decisão. 0 modelo é representado na Figura 1. 
CAMARGO, P. G. - Competência em Interpretação - Um breve estudo da interpretação em língua $B$.

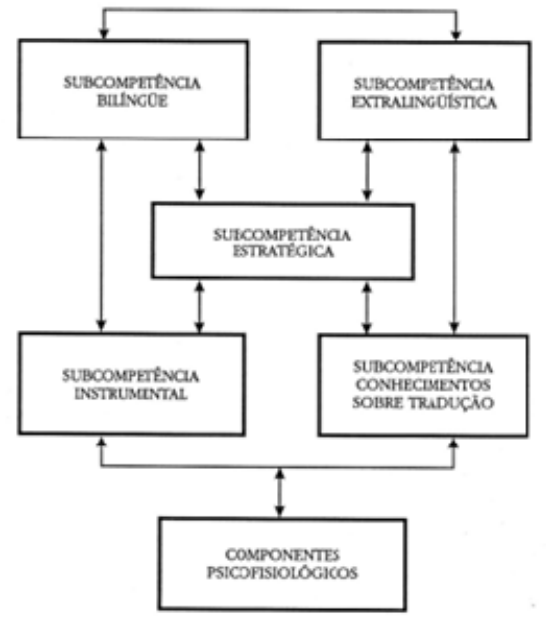

Figura 1- Modelo Holístico de CT do PACTE

HURTADO ALBIR 2005: 28-29

Para o PACTE, a CT não deriva automática e naturalmente do bilinguismo, pois é um conhecimento especializado:

Ficou claro que a CT é qualitativamente diferente da competência bilíngue e que é um conhecimento experto, no qual o conhecimento procedimental é predominante. Além disso, tornou-se ainda mais claro que a CT é composta por uma série de subcompetências que estão interrelacionadas e de forma hierárquica, com a subcompetência estratégica ocupando uma posição dominante. ${ }^{1}$ (PACTE 2003: 18)

O PACTE afirma haver conhecimento especializado em tradução:

O conhecimento declarativo consiste em saber o quê; é facilmente verbalizado, sua aquisição se dá pela exposição à informação e seu

1 It has become clear that translation competence is qualitatively different from bilingual competence and that it is expert knowledge in which procedural knowledge is predominant. Furthermore, it has become increasingly clear that translation competence is made up of a set of sub-competencies that are inter-related and hierarchic, with the strategic subcompetence occupying a dominant position. 
uso é normalmente controlado ( $p . e x .$, saber o endereço de sites que são úteis ao tradutor). Por outro lado, o conhecimento procedimental consiste em saber como; é difícil de ser verbalizado, é adquirido através da prática e seu uso é principalmente automático ( $p$. ex., saber como utilizar uma página eletrônica para garantir a precisão e a economia). Os procedimentos pelos quais esses conhecimentos são adquiridos ou construídos (estratégias e técnicas) são muito importantes. (PACTE 2003: 4) ${ }^{2}$

Os conhecimentos declarativos e procedimentais vão se aprimorando ao longo do aprendizado, seja esse motivado ou não; portanto, a partir da experiência com tradução. Ainda, os dados para a geração e validação do modelo incluem "o processo de tradução e o produto de traduções diretas e reversas (...). A decisão de se incluir traduções reversas foi tomada a fim de determinar as características da competência tradutória em relação à

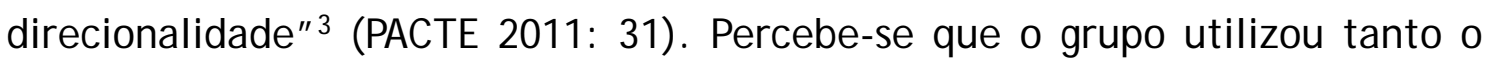
processo quanto o produto das traduções para a análise dos dados, o que corrobora o modelo apresentado, pois a hipótese do grupo é que 0 conhecimento especializado em tradução reflete-se tanto no processo quanto no produto.

Se a CT envolve processo e produto, nos questionamos a respeito da interpretação. Podemos dizer que o modelo de CT do PACTE aplica-se à interpretação ou haveria outras subcompetências a serem incluídas em um possível modelo para interpretação?

2 Declarative knowledge consists of knowing what: it is easily verbalised; it is acquired by being exposed to information and its use is normally controlled (e.g., knowing the addresses of web pages that are useful for translator documentation). On the other hand, procedural knowledge consists of knowing how: it is difficult to verbalise; it is acquired through practice and its use is mainly automatic (e.g., knowing how to use a web page to guarantee a translation's precision and economy). The procedures with which this knowledge is acquired or built (strategies and techniques) are very important.

3 The translation process and the translation product in inverse and direct translations involving six languages combinations (...) To decision to include data on both reverse and direct translation was made in order to determine the characteristics of translation competence in relation to directionality. 
CAMARGo, P.G. - Competência em Interpretação - Um breve estudo da interpretação em língua $B$.

A fim de responder à pergunta proposta, partimos da definição de interpretação e da análise do lugar que ela ocupa no campo dos Estudos da Tradução. Podemos afirmar que, tecnicamente, empregam-se os termos tradutor e tradução quando entramos em contato com um texto escrito, e interpretação e intérprete quando nos referimos aos textos orais; portanto, distanciamo-nos do senso comum que assume tradutor e tradução para ambos os tipos de textos. PöCHHACKER, em 1995, escreveu

As atividades profissionais da tradução e da interpretação podem, em muitos aspectos, ser consideradas gêmeas idênticas. Conceitualmente, podem ainda ser consideradas como dois lados da mesma moeda. ${ }^{4}$ (PÖCHHACKER 1995: 31)

0 mesmo autor retoma a discussão em 2010

Outro pressuposto básico é o de que a interpretação é uma forma de tradução, no seu sentido amplo, e que os Estudos da Interpretação como disciplina, mesmo que abertos a uma variedade de abordagens interdisciplinares, têm um lugar no amplo campo dos Estudos da Tradução. (PÖCHHACKER 2010: 62)

Por estarem no amplo campo dos Estudos da Tradução, há uma crença de que sejam atividades de mesma natureza e intercambiáveis, ou seja, o profissional tradutor seria também intérprete, e o contrário deveria ser válido, o que nem sempre é comprovado profissionalmente, pois temos profissionais que atuam somente como tradutores ou somente como intérpretes. Esse fato, segundo GILE (1995), relaciona-se à necessidade do intérprete de coordenar vários esforços de capacidade processual ao

\footnotetext{
${ }^{4}$ The professional activities of translation and interpreting can, in many respects, be regarded as fraternal twins. Conceptually, they can even be considered as two sides of the same coin.
} 
interpretar, diferentemente de como os esforços são coordenados pelo tradutor durante a tradução.

Em face de tal afirmação, quais seriam as competências requeridas de um intérprete? Primeiramente, o intérprete, para que possa interpretar, deve ser capaz de receber e entender a mensagem na língua fonte, ou língua de partida, e, consequentemente, expressar o significado na língua meta, ou língua de chegada. Para que tal feito seja possível, o intérprete desenvolverá uma série de atividades cognitivas de processamento da mensagem. Entre essas atividades, podemos citar a compreensão da mensagem, a análise da mensagem em relação ao seu significado e a reformulação da mensagem na língua de chegada ou língua meta.

GILE (1995 [2a ed. 2009]) não nomeia uma competência ou subcompetências, mas oferece uma descrição dos componentes que julga necessários para um conhecimento especializado em tradução: bom domínio das línguas passivas, bom comando de suas línguas ativas, conhecimento dos assuntos dos textos ou dos discursos que processam, e saber traduzir (GILE 1995: 4). 0 autor ainda desenvolveu um modelo a ser aplicado à interpretação e o nomeou Modelo dos Esforços. 0 modelo não pretendia estudar somente 0 processo de interpretação, como acontecia em modelos anteriores, mas sim explicar as ocorrências de erros e omissões; por outro lado, não se pode negar que o modelo proposto baseava-se em conceitos das ciências cognitivas. GILE (1999: 154) afirma que "com um mínimo de conhecimento sobre a arquitetura cognitiva, é possível desenvolver um conjunto de modelos com potencial explanatório e preditivo no nível do desempenho da interpretação" 5 .

O Modelo dos Esforços foi desenvolvido a partir da intuição do autor, de observações sobre a capacidade de processamento durante a interpretação. 0 modelo comporta duas premissas essenciais (GILE 1995: 161):

\footnotetext{
${ }^{5}$ The underlying idea is that with minimal assumptions about cognitive architecture, it is possible to come up with a set of models with explanatory and predictive potential on the level of actual interpreting performance.
} 
1. A interpretação requer alguma forma de "energia" mental que somente está disponível em quantidade limitada;

2. A interpretação consome quase toda essa energia mental e, às vezes, requer mais do que o disponível, o que resulta em deteriorações do desempenho.

A articulação dessas premissas gerou os componentes do modelo, denominados esforços. "A partir de minhas observações sobre a interpretação simultânea, imaginei um modelo segundo o qual ela é constituída por três componentes ou esforços principais: um componente de audição e análise, um componente de produção de discurso oral e um componente da memória de curto prazo" ${ }^{6}$. (GILE 1995: 162, destaques do autor).

0 intérprete conduzirá dois tipos de operações durante a interpretação: as operações automáticas e as não automáticas. As operações são principalmente não automáticas na interpretação, uma vez que o intérprete deve processar a informação muito além do nível léxico; portanto, tal processamento requererá esforços por parte do intérprete. Parece evidente que esse profissional sofrerá as restrições impostas pela palestra (ambiente) e pelo palestrante. Neste ponto, há uma diferença em relação à tradução, pois o intérprete não é senhor de sua própria organização e nem da sequência de informações e ideias, assim "os intérpretes precisam seguir o rumo e a velocidade escolhidos pelo orador". (GILE 1995: 166).

Durante as fases da interpretação, o intérprete realiza a versão final na primeira produção. Eventualmente correções são possíveis, mas de forma muito controlada e em nível menor, diferentemente do tradutor que poderá reorganizar e revisar seu trabalho durante as fases de tradução. GILE (idem)

\footnotetext{
${ }^{6}$ From my observation of simultaneous interpretation, I imagined it could probably be modeled as consisting of three main components or Efforts: a listening and analysis component, a speech production component, and a short-term memory component
} 
afirma que a interpretação difere da tradução especialmente por ser menos exigente em relação à terminologia e também à "correção" textual. Além disso, em interpretações de conferência, boa parte da informação está disponível para o intérprete no momento da tarefa, seja por meio de documentos ou por conta da proximidade com as pessoas da área.

Apesar do modelo de CT do PACTE (2003) e do Modelo dos Esforços de GILE (1995) não estarem intimamente ligados, ambos defendem existir certas subcompetências necessárias à tradução e à interpretação. No entanto, parece haver diferenças entre a tradução e a interpretação, principalmente em relação às restrições de tempo para a conclusão das tarefas de tradução e de interpretação.

Uma das questões principais da restrição de tempo em interpretação é que os conhecimentos necessários devem estar com o intérprete durante a interpretação, portanto, devem ser adquiridos anteriormente; enquanto que na tradução, é possível adquirir o conhecimento no decorrer da tarefa. 0 mesmo se dá em relação aos conhecimentos linguísticos, embora a subcompetência bilíngue proposta pelo PACTE deva estar desenvolvida, ainda assim é possível adquirir conhecimentos e verificar a adequação de um componente linguístico durante a tradução. Já na interpretação, o conhecimento linguístico não pode ser atualizado no momento da tarefa. No entanto, para que a interpretação seja possível, presume-se que o intérprete compreenda as duas línguas, conforme discutem PADILLA e MARTIN (1992: 197):

Para o intérprete, o processo de compreensão é muito mais complicado. Ele não tem tempo de usar dicionários ou consultar um especialista. A única maneira em que 0 intérprete pode afetar 0 processo de compreensão é tomando atitudes previamente, antes que a mensagem seja realmente comunicada, por intermédio da preparação exaustiva, tanto lexical como conceitual, a respeito do assunto envolvido. 
CAMARGo, P.G. - Competência em Interpretação - Um breve estudo da interpretação em língua $B$.

Questão mais delicada ainda é a da interpretação em língua B, pois tanto o conhecimento linguístico quanto as demais subcompetências ou esforços devem estar disponíveis para serem acessados e prontamente utilizados.

\title{
2. A interpretação em língua $B$
}

Iniciaremos pela definição de língua A e língua B. A AllC, Associação Internacional de Intérpretes de Conferência, utiliza as seguintes definições:

Língua A: A língua materna do intérprete (ou outra língua rigorosamente equivalente à língua materna), para a qual o intérprete pode interpretar a partir de todas as suas outras línguas em ambos os modos de interpretação, simultâneo e consecutivo. Todos os membros têm pelo menos uma língua "A", mas podem ter mais do que uma.

Língua B: Uma língua, além da língua materna, que o intérprete domina perfeitamente e para a qual interpreta a partir de uma ou mais das suas outras línguas. Alguns intérpretes só interpretam para uma língua "B" em um dos dois modos de interpretação. Segundo GILE (2005), essa sempre foi uma questão amplamente discutida na interpretação, ou seja, se o intérprete deve ou não interpretar para sua língua $B$ e quais são as restrições a ele impostas quando o faz.

PöCHHACKeR (2013: 21) ressalta que

\begin{abstract}
A tradição ocidental da interpretação de conferência favorece a interpretação simultânea das línguas B e C para a língua A do intérprete. A interpretação das línguas B e C, ou interpretação em retour (interpretação inversa), embora amplamente praticada nos mercados 'locais', não é aceita igualmente para interpretação simultânea em organizações internacionais [grifo do autor]?
\end{abstract}

\footnotetext{
7 The western tradition of conference interpreting has favored simultaneous interpreting from B or C languages into an interpreter's A language. A-to-B interpreting, or retour interpreting ('return interpreting') though widely practiced on the 'local' or private market, has not equally been accepted for simultaneous interpreting in international organizations.
} 
Uma explicação plausível para essa discussão é a de que a transferência pode ser afetada em determinados eventos comunicativos (PÖCHHACKER ibidem). No entanto, mercados locais utilizam a interpretação inversa em conferências, conforme relata TAKEDA (2010): “(...) a interpretação simultânea para a língua B é parte da realidade do mercado para os intérpretes de japonês, chinês, coreano, russo e espanhol. ${ }^{8 "}$ Apesar de não haver estudos conclusivos no par de línguas português-inglês, podemos afirmar que o mesmo acontece no Brasil, ou seja, os intérpretes são solicitados a interpretar para a língua $B$ com frequência.

A abordagem da direcionalidade em interpretação vem sempre à baila na literatura especializada devido à competência linguística que se julga ser necessária à interpretação.

\section{1 A subcompetência linguística}

Diferentemente da tradução, em que é possível ensinar o aluno a traduzir ao mesmo tempo em que se ensina língua (cf. SCHÄFFNER, 2000), na interpretação, especialmente na de conferência, "o requisito básico é que a aquisição da língua deva preceder o treinamento em interpretação." ${ }^{9}$ (PöCHHACKER idem:180). Portanto, o grau de competência bilíngue amplia-se para a interpretação de conferência, até mesmo nos estágios iniciais de aprendizagem. Essa afirmação nos leva a pensar na relação entre estágios de desenvolvimento de tradutores novatos e tradutores expertos, uma vez que a subcompetência linguística também poderá ser ensinada e aperfeiçoada, ao passo que as demais vão sendo adquiridas. Na interpretação, caso o interesse seja pela interpretação de conferência, a subcompetência linguística deve ser

\footnotetext{
8 (...) SI into B is part of the market reality for Chinese, Japanese, Korean, Russian and Spanish interpreters

${ }^{9}$ For conference interpreting, the basic tenet is that language acquisition must precede training in interpreting
} 
primeiramente adquirida, portanto parece não haver possibilidade de um aprendizado de língua e de interpretação simultânea concomitantemente, uma vez que a simultaneidade na interpretação tem como material primordial o texto oral em um idioma que remete diretamente a outro, tanto na interpretação $A>B$ quanto na $B>A$.

Dado o desnivelamento em relação à subcompetência linguística, analisaremos as demais subcompetências propostas pelo grupo PACTE em relação à interpretação a fim de discutir uma possível proposta de competência para interpretação.

\subsection{A subcompetência instrumental}

Para analisar a subcompetência instrumental, nos apoiamos no referencial teórico do PACTE ao que diz respeito a todos os aparatos dos quais o tradutor possa lançar mão para auxiliá-lo em uma tradução. São muitos, é verdade: dicionários, sites de busca, enciclopédias, entre outros. $\mathrm{Na}$ interpretação de conferência, a subcompetência instrumental também se faz presente, no entanto, sua construção é anterior ao momento do evento. 0 intérprete deverá se preparar antes do evento e, de fato, utilizará todos os recursos disponíveis. Diferentemente da tradução, na interpretação as informações deverão ser armazenadas na memória a fim de estarem disponíveis no momento da interpretação. Embora autores como PyM (2009) afirmem que é necessário ao intérprete ter acesso à memória eletrônica na cabine de interpretação, muito da mensagem entregue virá da memória criada pelo intérprete durante a fase de preparação para a conferência. Até mesmo a memória eletrônica deverá apresentar uma configuração que permita ao intérprete acessá-la, por questões lógicas de tempo e disponibilidade, como, por exemplo, um glossário previamente organizado. 


\subsection{0 conhecimento sobre interpretação}

Se no modelo de CT apresentado pelo PACTE em 2003, o conhecimento sobre tradução tem status de uma subcompetência, na interpretação não poderia ser diferente. 0 intérprete deve conhecer o mercado de trabalho, suas restrições, as necessidades e os modos de interpretação.

Conhecer os modos de interpretação a fundo pode auxiliá-lo na escolha do mais apropriado para determinada situação, o que garantirá condições adequadas de trabalho. Atualmente, são vários os modos de interpretação disponíveis no mercado, alguns ainda pouco desenvolvidos, como é o caso da interpretação midiática, apenas para citar um exemplo. Devemos, ainda, considerar que novos modos podem surgir dependendo da demanda, portanto, o intérprete deve saber pesquisar e estar atualizado.

\subsection{A subcompetência extralinguística}

Tanto 0 tradutor quanto 0 intérprete estarão expostos a diversos componentes extralinguísticos ao traduzirem ou interpretarem. Portanto, no modelo do PACTE, a subcompetência extralinguística se faz presente e atua durante o processo de tradução. Como ela atua em interpretação?

Os conhecimentos extralinguísticos em interpretação foram primeiramente definidos na Teoria dos Sentidos (Théorie du Sens) por Danica SLESKOVITCH e Mariane LedeRER. As autoras acreditam que, para ser possível interpretar, o intérprete deve operacionalizar uma fusão de componentes linguísticos e de componentes extralinguísticos, pois somente assim é possível transmitir sentido.

LEDERER afirma 
CAMARGO, P.G. - Competência em Interpretação - Um breve estudo da interpretação em língua $B$.

O conhecimento prévio é uma expressão vazia que abrange diversos "complementos cognitivos" que nos ajudam a entender o discurso. Esses complementos cognitivos incluem conhecimento de mundo, do momento, do lugar, das circunstâncias nas quais um discurso é formulado, da memória do que foi dito anteriormente, do conhecimento de quem é o locutor e de quem são os ouvintes (LEDERER 1990: 53; destaques da autora $)^{10}$.

Ao interpretar, principalmente em língua $B$, o intérprete deve possuir uma quantidade grande de conhecimentos extralinguísticos, uma vez que não é possível parar para refletir sobre o melhor uso, devido ao prejuízo causado à plateia quanto ao entendimento.

Um exemplo da importância desse tipo de conhecimento pode ser fornecido quando um palestrante, usando a língua inglesa para palestrar, utiliza exemplos de esportes pouco conhecidos no Brasil como o baseball ou 0 cricket. Cabe ao intérprete entender e adequar para a plateia que o escuta em português. No entanto, se 0 intérprete não possuir conhecimentos extralinguísticos, ele poderá incorrer em uma omissão que será prejudicial para o entendimento contextual geral.

\subsection{A subcompetência estratégica}

Como vimos no modelo do PACTE, a subcompetência estratégica ocupa uma posição central, pois é ela que regula as demais durante o processo de tradução. Para a interpretação, teríamos estratégias utilizadas pelos intérpretes na cabine de interpretação. No entanto, parece haver uma diferença, pois a técnica de interpretação para cabine é treinada de forma

10 Background knowledge is a blanket expression covering a number of 'cognitive complements' that help us understand speech. These include knowledge of the world, of time, place, of the circumstances out of which a speech arises, memory of things said previously, knowing who the speaker is and who the listeners are. 
consistente na formação de intérpretes. É possível perceber que há partes mais estáveis e outras não tão estáveis ao longo da interpretação, o que nos levaria a indagar se a estratégia funciona de mesma forma durante todo 0 processo.

Por essa razão, poderíamos dizer que a subcompetência estratégica também ocupa um papel central na elaboração de uma interpretação, gerenciando e garantindo a eficácia do processo. Assim, ela teria uma atuação dupla: antes de e durante o processo.

\subsection{Os componentes psicofisiológicos}

$\mathrm{Na}$ interpretação, os componentes fisiológicos são essenciais, pois os componentes cognitivos, como memória, atenção, percepção e emoção interagem durante todo 0 processo interpretativo. 0 intérprete deve desenvolver a memória para conseguir interpretar. Ainda, a percepção para elementos linguísticos, extralinguísticos e para os estímulos presentes no ambiente devem atuar a fim de auxiliar 0 intérprete na busca pela interpretação mais adequada. A capacidade de análise e síntese é primordial, especialmente em interpretação simultânea. Como o intérprete precisará fazer adições e omissões para facilitar o entendimento da plateia, a síntese será uma aliada para compensar partes maiores, nas quais obrigatoriamente houve uma adição. SHLESINGER, (1999: 69) ao comentar sobre a capacidade de síntese, escreve:

Não se precisa reproduzir todo elemento de toda frase. É apropriado para o intérprete simultâneo produzir somente o sentido subjacente na frase. Isso é aceitável e muitas vezes até desejável, já que uma interpretação de todo elemento separado de uma frase é propensa a esgotar os recursos cognitivos do intérprete e pode também ultrapassar a capacidade do ouvinte de processar o insumo na língua alvo. 
Percebemos que a adequação na interpretação é necessária para facilitar o trabalho do intérprete e para permitir que a plateia receba um discurso de acordo com a sua capacidade de processamento.

\section{Competência na interpretação em língua B?}

Frente à exposição do modelo de CT do grupo PACTE e dos postulados do Modelo dos Esforços de GiLE, é possível inferir que a tradução e a interpretação, além estarem amparadas por arcabouços teóricos bem próximos, envolvem algumas subcompetências similares, mas que parecem se organizar de forma diferente, uma vez que a restrição do tempo é altamente influenciável no produto final da interpretação. Sabemos que a restrição temporal também se faz presente na tradução, mas na interpretação parece haver maior implicação, pois ocorre durante todo o processo.

GILE (1995: 186) afirma que "as restrições de tempo em tradução podem ser consideradas virtualmente não existentes se comparadas às da interpretação. ${ }^{11 "}$

Parece-nos correto afirmar que as subcompetências estão presentes na interpretação da mesma forma que na tradução, porém o fator tempo e prontidão de resposta exigidos do intérprete poderiam alterar a configuração da CT propondo dois momentos de construção de uma competência interpretativa, ou seja, o momento anterior ao evento (preparação) e 0 momento de atuação (interpretação). No entanto, seria ousadia de nossa parte propor quaisquer modificações, visto que realizamos apenas um breve

\footnotetext{
${ }^{11}$ Time constraints in translation can be considered virtually nonexistent when compared to the time constraints in interpretation.
} 
estudo. Futuros estudos sobre o momento de construção de uma competência interpretativa e sobre o seu desenvolvimento poderão ser extremamente úteis para a comunidade de intérpretes atuando em diferentes eventos e em diferentes mercados.

\section{Considerações Finais}

Neste artigo, buscamos estudar o modelo de CT aplicado à tradução proposto pelo grupo PACTE (2003) bem como o Modelo dos Esforços de Daniel GILE (1995, 2009), proposta feita para a interpretação, especificamente ao modelo para interpretação simultânea (temos consciência da existência de um modelo a ser aplicado em interpretação consecutiva). 0 foco do artigo esteve na construção de uma competência interpretativa, em analogia à competência tradutória, considerando a interpretação em língua $B$, ou seja, em língua não nativa, conforme definição da AllC (exposta anteriormente no escopo deste artigo).

Ao discutirmos a questão da subcompetência linguística, encontramos na literatura de interpretação a afirmação de que é primordial que 0 intérprete a adquira antes de aprender a interpretar, especialmente na interpretação simultânea cujo entendimento do discurso e sua possível entrega devem ocorrer simultaneamente ao palestrante. Provavelmente, essa seja a questão de maior desnível em relação ao aprendizado e estabelecimento de uma competência tradutória e uma competência interpretativa.

Por outro lado, as demais subcompetências sugerem desempenhar um papel bem próximo tanto na tradução quanto na interpretação, apesar da diferença quanto ao momento do desenvolvimento de cada uma. Quanto aos 
componentes psicofisiológicos, acreditamos serem de grande valia para 0 tradutor e, de mesma feita, para o intérprete, uma vez que regulam ações de atenção, memória, entre outras.

Além disso, vale lembrar que a interpretação simultânea é sempre não editável, ou seja, assim que o intérprete receber a mensagem deverá entregá-la em outro idioma sem opção de ajustes ou edições como acontece na tradução.

A interpretação, especialmente a simultânea, devido às suas características, e em língua $B$, devido à discussão de sua aplicabilidade, é um processo complexo de produção da linguagem que suscita uma grande demanda de pesquisa em relação às competências a serem desenvolvidas na formação de intérpretes. É possível, no entanto, utilizar o modelo de competência tradutória como ponto de partida para aprofundar tal estudo comparativo.

\section{Referências bibliográficas}

Allc - Associação Internacional de Intérpretes de Conferência - Disponível em: http:// www. aiicbrasil.com. br/ . Diversos acessos entre novembro e DEZEMBRO DE 2013.

Cintrão, H. P. Colocar Lupas, Transcriar Mapas: iniciando 0 desenvolvimento da competência tradutória em níveis básicos de espanhol como língua estrangeira. 2006. Tese (Doutorado em Letras) - Faculdade de Filosofia, Letras e Ciências Humanas, Universidade de São Paulo, 2006. Disponível em: http:// www. teses. usp. br/teses/ disponiveis/ 8/ 8145/tde08082007-145636/. Diversos acessos entre novembro e dezembro de 2013.

COMISSÃO EUROPÉIA. A combinação linguística do intérprete. Disponível em: http:/ / ec. europa. eu/ dgs/ scic/ what-is-conference-interpreting/ languagecombination/index_pt.htm. Acesso em 29 e 30/11/ 2013. 
GILE, D. Basic Concepts and Models for Interpreter and Translator Training. Amsterdam/ Philadelphia: J ohn Benjamins, 2009 [1995].

Variability in the perception of fidelity in simultaneous interpretation. In: Hermes 22, J ournal of Linguistics, 1999. p.51-80.

HuRTADo AlBiR, A. A aquisição da competência tradutória: Aspectos teóricos e didáticos. In: Pagano, A.; Magalhães, C.; Alves, F. (Orgs.). Competência em tradução: cognição e discurso. Belo Horizonte: Editora UFMG, 2005. p. 19-57.

LEDERER, M. "The Role of Cognitive Complements in Interpreting". In: BOWEN, David \& BOWEN, Margareta (orgs.). Interpreting - Yesterday, Today, and Tomorrow. ATA Monograph Series, v. IV. Binghamton: State University of New York, 1990, p. 53-60.

PACTE (Processo de Adquisición de la Competencia Traductora y su Evaluación). Building a translation competence model. In: ALVES, Fabio (ed.). Triangulating translation. Amsterdam/ Philadelphia: J onh Benjamins, 2003. p. 43-66.

Padilla, P.; Martin, A. Similarities between interpreting and translation: implications for teaching. In: DoL ERUP, C.; LINDEGAARD, A. (Org.). Teaching translation and interpreting: training, talent and experience. AmsterdAM: J ohn Benjamins, 1992.

PÖCHHACKER, F. Simultaneous Interpreting: A Functionalist Perspective. In: Hermes, Journal of Linguistics, 1995. p.31-54.

Routledge, 2004.

Introducing Interpreting Studies. London/ New York:

. Conexões Fundamentais. Trad. Mylene Queiroz. In: Scientia Traductionis, n.7, 2010. p. 61-74. Disponível em: https:// periodicos. ufsc. br/ index. php/ scientia/ article/ download/ .../ 12934. Múltiplos acessos em dezembro de 2013.

PYM, A. On Omissions in Simultaneous Interpreting: Risk Analysis of a hidden effort. In: HANSEN, G.; ChESTERMAN, A. (Orgs. Efforts and Models in Interpreting and Translation Research: A tribute to Daniel Gile. Amsterdam: John Benjamins Publishing, 2009. p. 83-108. 
CAMARGO, P. G. - Competência em Interpretação - Um breve estudo da interpretação em língua $B$.

SCHÄFFNER, C. Running before walking? Designing a Translation Programme at Undergraduate Level. In: SCHÄFFNER, C.; ADAB, Bervely (eds). Developing Translation Competence. Amsterdam/ Philadelphia: J ohn Benjamins, 2000.

SHLESINGER, M. Norms, Strategies and Constraints: How do we tell them apart? In: LUGRIS, A.A \& OCAMPO, A. F. (eds.): Anovar/ Anosar: Estudios de Traduccion E Interpretacion. Vigo, Universidade de Vigo, 1999. p. 65-77.

TAKEDA, K. What interpreting teachers can learn from students: A case study. In: The International J ournal for Translation \& Interpreting Research, vol. 2, n.01(2010). California: Monterey Institute of International Studies. Disponível em:

http:// www. trans-int. org/ index. php/ transint/ article/ viewfile 